\title{
Significados atribuídos por profissionais da Psicologia à prática da mediação familiar
}

\author{
Meanings attributed by Psychology professionals \\ to the practice of family mediation \\ Significados atribuidos por profesionales de la Psicología \\ a la práctica de la mediación familiar
}

\author{
Loridane Meotti" \\ Aline Bogoni Costa**
}

\section{Resumo}

Entende-se por significado do trabalho as representações que uma pessoa elabora sobre suas atividades de modo individual, grupal e social. Este artigo, de caráter qualitativo, objetivou identificar os significados atribuídos por profissionais da Psicologia à prática da mediação familiar no contexto judicial do Estado de Santa Catarina. O serviço de mediação familiar ocorre em 73 locais dos 113 Fóruns de Justiça existentes no Estado, sendo que 22 profissionais ocupam o cargo de psicólogo(a) e, destes, 4 (quatro), os quais foram participantes desta pesquisa, estão no Serviço de Mediação Familiar. Aplicou-se um questionário com perguntas fechadas e abertas, cujos dados foram interpretados por meio da análise de conteúdo. Foram identificadas cinco categorias para o significado do trabalho de mediação familiar, sendo elas: 1) a mediação familiar como complexa e difícil; 2) a mediação familiar como uma oportunidade de adquirir novos conhecimentos; 3) a mediação familiar como uma atuação importante ao desenvolvimento da Psicologia; 4) a mediação familiar como central à cultura do trabalho ampliado na Psicologia; $e, 5)$ a mediação familiar como desafiadora e ampla. Discutiu-se acerca do reduzido quadro de profissionais da Psicologia nesta atuação no Estado, o qual consiste-se em um desafio à ampliação desta inserção. E, por fim, a relevância da interdisciplinaridade e as potencialidades da atuação da Psicologia.

Palavras-chave: Significados; Trabalho; Mediação Familiar; Psicologia.

* Universidade do Oeste de Santa Catarina (UNOESC). E-mail: loridane.meotti@gmail.com

** Universidade do Oeste de Santa Catarina (UNOESC). E-mail: aline.costa@unoesc.edu.br 


\section{Abstract}

The meaning of work is understood as the representations that a person elaborates about his activities in an individual, group and social way. This qualitative article aimed to identify the meanings attributed by Psychology professionals to the practice of family mediation in the judicial context of the State of Santa Catarina. The family mediation service takes place in 73 places of the 113 Justice Forums existing in the State, with 22 professionals occupying the position of psychologist (a) and, of these, 4 (four) who participated in this research are in the Family Mediation Service. A questionnaire was applied with closed and open questions and data were interpreted through content analysis. Five categories were identified for the meaning of family mediation work: (1) family mediation as complex and difficult; 2) family mediation as an opportunity to acquire new knowledge; 3) family mediation as an important action in the development of Psychology; 4) family mediation as central to the expanded work culture in Psychology; and, 5) family mediation as challenging and broad. It was discussed, The lack of Psychology professionals at work in the state and how challenging expansion is. Finally, the relevance of interdisciplinarity and the amount of work potential at stake for a Psychology professional.

Keywords: Meanings; Job; Family Mediation; Psychology.

\section{Resumen}

Se entiende por significado del trabajo las representaciones que una persona elabora sobre sus actividades de modo individual, grupal y social. Este artículo de carácter cualitativo objetivó identificar los significados atribuidos por profesionales de la Psicología a la práctica de la mediación familiar en el contexto judicial del Estado de Santa Catarina. El servicio de mediación familiar ocurre en 73 locales de los 113 Foros de Justicia existentes en el Estado, siendo que 22 profesionales ocupan el cargo de psicólogo (a) y de éstos, 4 (cuatro), los cuales participaron de esta investigación, están en el Servicio de Mediación Familiar. Se aplicó un cuestionario con preguntas cerradas y abiertas, cuyos datos fueron interpretados por medio del análisis de contenido. Se identificaron cinco categorías para el significado del trabajo de mediación familiar, siendo ellas: 1) la mediación familiar como compleja y difícil; 2) la mediación familiar como una oportunidad de adquirir nuevos conocimientos; 3) la mediación familiar como una actuación importante para el desarrollo de la Psicología; 4) la mediación familiar como central a la cultura del trabajo ampliado en la Psicología; y 5) la mediación familiar como desafiadora y amplia. Se discutió, sobre el reducido cuadro de profesionales de la Psicología que actúan en este campo, en el Estado, siendo así un desafio la ampliación de esta inserción. $Y$, por fin, la relevancia de la interdisciplinaridad y las potencialidades de la actuación de la Psicología.

Palabras clave: Significados; Trabajo; Mediación Familiar; Psicología. 
Este artigo apresenta os resultados de um estudo que objetivou identificar os significados atribuídos por profissionais da Psicologia à prática da mediação familiar no contexto judicial, no Estado de Santa Catarina. Ao longo da história da humanidade, paradoxos, oposições e divergências transformaram as relações e os modos de vida (Gomes, 2013). As situações de conflitos são inerentes à existência humana, jamais deixarão de existir (Vieira, 2014) e ocorrem na sociedade, em especial, devido à inexistência ou à dificuldade de negociação das diferenças (Melo, 2013), constituindo-se por falhas ou rupturas no processo entre as partes que se comunicam, caracterizadas pela incapacidade de emitir e receber informações. Tais situações podem, ao mesmo tempo, ser uma possibilidade de decisão, inaugurando, assim, a oportunidade de transformar a realidade social (Trindade, 2014).

Em termos culturais, há uma variedade de mecanismos para a resposta aos conflitos; porém, muitos desses são inadequados, como a postura de negação da existência do conflito, o rompimento das relações, a repulsa como vingança e o uso da violência. Situações de conflitos mal resolvidas revelam diversos sentimentos, podendo impactar em dor e sofrimento humano (Nunes, 2016). A busca pelo Direito para a solução de conflitos intensificou-se nas últimas décadas, como um terceiro que participa desse processo psicológico e social, sendo entendido como referência, corpo e voz para o julgamento de valores e a produção de condições alternativas para se chegar a acordos e dissolver as diferenças (Melo, 2013). No entanto, o Direito, em sua prática, não visa abarcar as questões subjetivas, pois é uma ciência que se utiliza de Leis e procura pautar-se de certa objetividade para a tomada de decisão (Mello \& Jaeger, 2015). O diálogo assertivo ainda é um aprendizado incipiente na tradição brasileira, que é baseada em litígio (Nunes, 2016), sendo que o instrumento de mediação de conflitos tem se consolidado como uma das alternativas.

A mediação, palavra derivada do verbo latino mediare, com o significado de mediar, intervir, colocar-se no meio (Vieiera, 2010), constitui-se como um terceiro imparcial que facilita o diálogo assertivo, promovendo o entendimento das diferenças e levando as partes à busca por soluções criativas para o acordo comum, por meio da sensibilidade da escuta e da crença no potencial de transformação frente ao vasto conteúdo subjetivo 
impregnado em situações de litígio (Müller, 2007). Tal instrumento teve sua institucionalização na administração pública, em especial, no Poder Judiciário, no final da década de 1970, nos Estados Unidos e Europa. Historicamente, a mediação está intimamente vinculada ao movimento de acesso da sociedade à Justiça (Conselho Nacional de Justiça [CNJ], 2016a). A mediação orienta-se por duas tendências contraditórias, presentes desde a origem do movimento. Enquanto nos Estados Unidos a mediação correspondia a uma resposta capaz de trazer celeridade ao Judiciário, na França, ela teve sua origem pautada na transformação dos conflitos (Barbosa, 2002). Neste país, ela constitui-se como um instrumento amplo, flexível, horizontal e democrático, a partir do qual se busca trabalhar a autonomia das partes de modo consciente, a fim de que possam ressignificar suas diferenças e construir as melhores soluções comuns (Nunes, 2016). A partir dessa compreensão, a interface do Direito com a Psicologia torna-se potencial e essencial, no sentido da busca por compreender o sujeito em sua totalidade (Mello \& Jaeger, 2015). No entanto, como se caracteriza o cenário brasileiro e catarinense diante dessa potencialidade?

No Brasil, são expressivos os números de processos ajuizados anualmente. Em 2015, foram cerca de 102 milhões, contabilizando, ao término do mesmo ano, um estoque aproximado de 74 milhões de processos em tramitação. No Estado de Santa Catarina, no mesmo ano, 30,2\% dos assuntos mais recorrentes na justiça foram os processos cíveis, totalizando aproximadamente 186.226 processos, sendo que, destes, 21.641 referiram-se ao direito de família. Além da expressividade de casos, é preciso considerar a morosidade na tramitação dos assuntos de família, que variam de 2 a 5 anos (CNJ, 2016c).

Frente às demandas, constrói-se o paradigma de cumprir o Novo Código de Processo Civil e a Lei da Mediação, no qual foi estabelecido que a conciliação e a mediação são consideradas prioritárias; ou seja, deverá haver audiências prévias de conciliação e mediação como etapa obrigatória para todos os processos cíveis. Com a nova legislação, entende-se que o Estado brasileiro demonstrou seriedade em relação ao tema, com pretensão de um atendimento adequado à população (Nunes, 2016). Ademais, o Conselho Nacional de Justiça (2016b) contabilizou, no ano de 2015, cerca de 11\% de 
processos resolvidos por meio de acordos, fruto de conciliações e mediação, resultando em aproximadamente 2,9 milhões de processos finalizados de maneira auto compositiva em toda a Justiça brasileira. Infere-se, assim, a contribuição e a importância das vias consensuais de solução de conflito para a diminuição da litigiosidade.

Especificamente a mediação de conflitos familiares, interesse desse estudo, é considerada complexa, tendo em vista sua pluralidade, função ideológica, de transmissão de valores, de estabelecimento de papéis e padrões de comportamento, que serão repetidos ou não pelas gerações, e dos aspectos afetivos envolvidos, constituindo-se, assim, em um microssistema (Müller, 2007). Assim sendo, quando surgem conflitos no microssistema familiar, o diálogo, muitas vezes, já não é mais capaz de resolvê-los. Surge então, a necessidade de se buscar uma alternativa externa para a resolução desses problemas e a preservação das relações que serão continuadas, por exemplo, na guarda de crianças (Gondim, 2012; Santos \& Júnior, 2011).

Diante da complexidade dos conflitos familiares, a atuação de profissionais da Psicologia na mediação constitui-se em uma possibilidade terapêutica, pois trabalha na interface entre o subjetivo e o objetivo, valendo-se das transformações inerentes ao litígio, objetivando-se a mudança de comportamento das partes, que extrapola o ambiente jurídico (Melo, 2013), a valorização dos integrantes e da identidade familiar, evitando reincidências (Müller, 2007; Vieira, 2014). Quando o mediador possui formação em Psicologia, este dispõe de percepção e compreensão das vivências emocionais e inconscientes, bem como de repertório vasto de habilidades, técnicas e conhecimentos acerca da subjetividade humana, o que pode auxiliar no esclarecimento de pontos nodais ocorridos no processo de mediação e que interferem no estabelecimento da comunicação assertiva e possibilitar soluções antes não identificadas (Barbieri \& Leão, 2012; Cavalcante, 2015; Freitas et al., 2011; Melo, 2013).

Entretanto, embora de grande relevância, a atuação da Psicologia no âmbito do judiciário brasileiro é recente; ela iniciou-se nas décadas de 1980 e 1990 e ainda carece de ser intensificada (Santos, 2013; Nascimento, 2016). No Poder Judiciário de Santa Catarina relata-se que, em meados de 1986, foram iniciados os primeiros atendimentos psicológicos com servidores no 
contexto jurídico (Costa, 2006) e até 2014, havia 26 psicólogos efetivos, sendo que somente quatro atuavam no Serviço de Mediação Familiar (SMF), em suas respectivas comarcas (Otaran \& Amboni, 2015).

Tendo em vista a relevância dessa atuação e, em contrapartida, a inexpressiva participação dos profissionais nesta área, bem como as informações teóricas apresentadas, questionou-se, no presente estudo: quais os significados atribuídos à prática no SMF de profissionais da Psicologia que atuam no Poder Judiciário de Santa Catarina? Entende-se significados como sendo a representação que o indivíduo elabora de/sobre seu trabalho, ou seja, o significado do trabalho é visto como a representação social que a tarefa realizada tem para o indivíduo, no nível individual; pela identificação do trabalho com o resultado da tarefa, no nível do grupo; pelo sentimento de pertencer a uma classe unida, que realiza um trabalho em comum ou no nível social; pelo sentimento de realizar um trabalho que contribua à sociedade. O significado se diferencia do sentido, sendo, este último, definido por meio das dimensões de utilidade da tarefa, de autorrealização, de satisfação, pelo sentimento de desenvolvimento, pela evolução pessoal e profissional, bem como pela liberdade e autonomia ao realizar a tarefa (Tolfo \& Piccinini, 2007).

\section{MÉTODO}

\section{Caracterização, contexto e participantes da pesquisa}

A abordagem utilizada foi a qualitativa, que teve por intuito descrever e analisar experiências através de reflexões, discutindo as vivências pessoais e coletivas (Minayo, 2004). Sendo assim, essa abordagem trabalha com o universo de significações, motivos, aspirações, crenças, valores e atitudes, que correspondem a um espaço mais profundo das relações, necessitando assim, de um referencial de coleta e interpretação (Minayo, 2004).

O contexto da pesquisa foram os Fóruns de Justiça nos quais o SMF, programa do Judiciário e com previsão legal que objetiva o atendimento de conflitos familiares de uma forma mais acessível e menos traumática, está implantado ou em implantação. Deste modo, realizou-se busca prévia 
dos locais com o SMF, de acordo com informações do Poder Judiciário de Santa Catarina, constatando-se que o serviço ocorre em 73 locais dos 113 existentes (Poder Judiciário de Santa Catarina [PJSC], 2017).

Realizou-se, no período de abril e maio de 2017, um levantamento, por meio de contato eletrônico e/ou telefônico, junto a 22 profissionais que ocupam o cargo de psicólogo(a) no Poder Judiciário de Santa Catarina. Desses, apenas 4 (quatro) profissionais da Psicologia atuam no SMF, aqui denominados ficticiamente de E1, E2, E3 e E4, os quais aceitaram participar desta pesquisa. Assim sendo, a pesquisa abrangeu o total de profissionais nesta atuação no Estado de Santa Catarina.

\section{Coleta e análise de dados e informações}

No que se refere à coleta de dados, o instrumento utilizado foi um questionário elaborado pela pesquisadora com questões fechadas e abertas sobre a temática da pesquisa, o qual foi enviado por e-mail aos participantes. Diehl (2004), salienta que, por meio desse instrumento, o entrevistador segue um roteiro previamente estabelecido, ou seja, as perguntas feitas ao indivíduo são predeterminadas.

Realizou-se a análise de conteúdo, proposta por Bardin (2011), que corresponde a um conjunto de técnicas de análise das comunicações que utiliza procedimentos sistemáticos e objetivos de descrição do conteúdo das mensagens. É, portanto, um instrumento que oscila entre o rigor da suposta objetividade e a fecundidade da subjetividade, tendo por fim interpretá-los. Neste sentido, conforme Minayo (2004), o pesquisador está sempre procurando um texto por trás de outro, um texto que não está aparente já na primeira leitura e que precisa de uma metodologia para ser desvendado. Os procedimentos seguidos para a análise do conteúdo desta pesquisa foram, de acordo com Bardin (2011): a) pré-análise, que compreende a escolha e organização do material transcrito, com a realização de leitura inicial, possibilitando a identificação das questões norteadoras do material; b) exploração do material, realização de leituras recorrentes, 
com a identificação das unidades de registro e dos núcleos de conteúdo da pesquisa; c) tratamento dos resultados, por meio de reflexão sobre os núcleos de significados identificados.

\section{Aspectos éticos}

A pesquisa foi submetida e aprovada pelo Comitê de Ética em Pesquisa (CEP) da UNOESC, conforme parecer de número 2.148.751 e CAAE: 69707017.1.0000.5367. Os aspectos éticos de pesquisa com seres humanos presentes nas diretrizes da Resolução n. 466/2012, do Conselho Nacional de Saúde (CNS), foram integralmente seguidos. Devido à distância geográfica com os participantes, os esclarecimentos foram formalizados via e-mail e por contato telefônico, bem como as assinaturas do Termo de Consentimento Livre e Esclarecido, possibilitadas pela digitalização dos documentos.

\section{RESULTADOS E DISCUSSÃO}

\section{Caracterização dos participantes da pesquisa}

Evidenciou-se, por meio do levantamento prévio, que, dos 113 Fóruns de Justiça que integram o Poder Judiciário de Santa Catarina, o SMF ocorre em 73 desses locais, havendo poucos profissionais da Psicologia atuantes na função. O fato é explicado, conforme relato das participantes da pesquisa, pela quantidade reduzida de profissionais da categoria no Poder Judiciário de SC e, consequentemente, na prática da mediação.

Verificou-se que as participantes desta pesquisa são todas do sexo feminino, com idades entre 32 anos a 56 anos de idade. Estão lotadas no cargo de Psicóloga há 4 (quatro) a 9 (nove) anos, exercendo outras atividades além da mediação familiar, tais como: avaliação psicológica nos processos judiciais das diversas áreas (família, infância e juventude, criminal) e acompanhamento nos processos de adoção. Destas participantes, três cursaram Especialização, nas áreas de Psicologia Jurídica, Gestalt-Terapia, Recursos Humanos, Saúde Pública e Coletiva. 
Acerca do período de atuação no SMF, observou-se que eles foram distintos, porém recentes: E1 trabalha com mediação familiar há sete anos; E2, há quatro; E3, há quatro anos e seis meses; e E4, há seis anos. Em relação à capacitação para atuar no SMF, identificou-se uma variabilidade de carga horária, estipulada entre 12 e 180 horas. De acordo com o Módulo Teórico do CNJ (2016a), exige-se, no mínimo, 40 (quarenta) horas/aula, complementadas, necessariamente, pelo Módulo Prático (estágio supervisionado), com 60 (sessenta) a 100 (cem) horas. Compreendeu-se, assim, uma predominância de formação adequada para o exercício da mediação.

\section{Os significados atribuídos à prática profissional em SMF}

Os significados atribuídos pelas participantes à prática profissional no contexto judicial da mediação familiar foram identificados em cinco categorias, elencadas a seguir: categoria 1 - a prática da mediação familiar significada como complexa e difícil; categoria 2 - a prática da mediação familiar significada como uma oportunidade de adquirir novos conhecimentos; categoria 3 - a prática da mediação familiar significada como importante ao desenvolvimento da Psicologia; categoria 4 - a prática da mediação familiar significada como central para se fomentar a cultura do trabalho ampliado na Psicologia; e, categoria 5 - a prática da mediação familiar significada como desafiadora e ampla. As categorias identificadas serão apresentadas e discutidas nesta seção.

\section{Categoria 1: A prática da mediação familiar significada como complexa e difícil}

Nesta categoria de significados, o trabalho no SMF foi representado como sendo de alta complexidade e difícil de ser realizado, abrangendo questões como a desproporção do número de profissionais da categoria, a relação interdisciplinar com outras áreas de atuação, em especial no campo do Direito, o entendimento do procedimento de mediação de modo restritivo (efeito de celeridade aos processos) e a descaracterização das atividades profissionais na atuação em Psicologia. 
Identificaram-se menções recorrentes das entrevistadas à quantidade reduzida de profissionais da Psicologia no Poder Judiciário de Santa Catarina, bem como na atuação com a mediação familiar, conforme E2: "Há enxuto quadro de Psicólogos no Poder Judiciário. Existem muito mais profissionais do Serviço Social atuando na mediação, já que o quadro de profissionais dessa área é mais numeroso". A participante E3 também relata: "Há reduzido número de Psicólogos e pouco tempo de atuação desses profissionais no TJSC (cerca de 10 anos), quando comparado ao Assistente Social, por exemplo". Esses depoimentos corroboram com as demandas apresentadas nos movimentos do Conselho Regional de Psicologia, nos quais a escassez da categoria no campo Jurídico está em pauta. Segundo mapeamento realizado, 80\% das comarcas não possuem uma equipe multidisciplinar, formada por um psicólogo(a) e um assistente social, sendo que, atualmente, há 202 profissionais atuantes nestas duas categorias no Tribunal de Justiça do Estado, dos quais apenas 22 são psicólogas(os) (Conselho Regional de Psicologia [CRP], 2017). Por sua vez, somente quatro dos 22 psicólogos atuam com a mediação familiar, de acordo com o que foi levantado nesta pesquisa.

Percebeu-se que, em virtude do quadro reduzido de profissionais da Psicologia, houve ênfase das profissionais pesquisadas à sobrecarga de trabalho, que pode desencadear em prejuízos à saúde. As informações reforçam os achados de um estudo anterior (Otaran \& Amboni, 2014), em que identificaram-se, nos relatos dos psicólogos do TJSC, queixas relacionadas ao aumento progressivo de processos a serem atendidos e seu curto prazo de realização, demarcando uma sobrecarga de trabalho em razão da escassez de recursos humanos. Em vista disso e pela compreensão das demandas no contexto estudado, infere-se que pode haver um desvio de função para possibilitar a atuação do serviço de mediação familiar, podendo este ser um dos motivos para as dificuldades de realização do referido serviço.

Verificou-se, ainda, a dificuldade de distinção entre o fazer da Psicologia e a metodologia da mediação, uma vez que, a função de mediador é possível em diversas outras áreas e há poucas especificações na Psicologia para tal atuação. Como observado na Resolução n. 11/2001-TJ (Poder 
Judiciário de Santa Catarina [PJSC], 2017), que dispõe sobre a instituição do SMF, a atuação é possível aos profissionais da área de Assistência Social, Psicologia, Pedagogia e Direito. Diante disso, E1 e E3 explicaram:

No caso da mediação as práticas utilizadas devem ser as próprias da mediação, com o cuidado para não misturar com práticas terapêuticas ... as intervenções utilizadas por mim são a partir das técnicas próprias da mediação familiar, não faço uso de práticas psicológicas, pois naquele momento meu papel ser o de mediadora e não de psicóloga (E1).

Há dificuldade de separar a atuação enquanto profissional da Psicologia no Judiciário e a prática como mediador. O psicólogo, ao realizar a mediação, deve despir-se do fazer psicológico para atuar como mediador. Acho preocupante "misturar" as práticas (E3).

Compreendeu-se, a partir das falas, que não deve ser ofertado atendimento clínico nos procedimentos de mediação, mas, sim, deve ser favorecido o ambiente que propicie o diálogo. Diante disso, a natureza da ciência psicológica está, por si própria, relacionada à subjetividade humana e à relatividade das situações. Entretanto, a ausência da definição de seus limites é algo que, eventualmente, subestima seu real papel na sociedade (Otaran \& Amboni, 2014), o que pode ser evidenciado a partir das falas anteriormente apresentadas, das participantes E1 e E3.

Outra dificuldade enfrentada no cotidiano de trabalho descrita pelas participantes tem sido o desconhecimento e a resistência por parte dos profissionais do Direito frente aos procedimentos de mediação, conforme mencionaram E1 e E3: "Foi preciso esclarecer os operadores do Direito e, até mesmo, à população do que se tratava" (E1) e "Há uma negativa de muitas pessoas em relação à mediação, principalmente dos advogados. Com resistência de alguns profissionais do Direito, as partes envolvidas, muitas vezes, também não sentem estimuladas para uma sessão de mediação familiar" (E3).

No entanto, como exposto por Trindade (2017), é de relevância da Psicologia estimular o diálogo com os saberes do Direito, tanto quanto, as demais ciências. Porém, a fim de que isso ocorra, torna-se essencial a compreensão da complementariedade de uma área com a outra, esboçando 
assim, que a Psicologia é fundamental para o Direito e essencial para a Justiça. Nesta perspectiva, Nunes (2016) enfatiza a importância do trabalho interdisciplinar na mediação, o qual não deve ser reduzido em ameaça à independência das profissões, mas, sim, entendido como complementar à construção conjunta de significados, possibilitados pelo conhecimento de várias áreas.

Outro aspecto que confere, segundo as participantes, complexidade e dificuldade à atuação é a distorção do propósito da mediação, especificamente no que tange à busca por trazer celeridade aos processos no judiciário, de acordo com as afirmações seguintes: "A busca pela produtividade, primando pela produção de acordos ao invés do procedimento de mediação em si é uma dificuldade" (E1) e "Há o desafio relacionada à cultura do litígio, bem como, a ideia da necessidade de se alcançar um acordo judicial" (E2). Como explica Almeida (2017), pode haver uma leitura equivocada de muitas pessoas sobre o tema. A mediação é um serviço que não foi pensado, à priori, na tentativa de desafogar o judiciário, mas, sim, como um instrumento para a solução de controvérsia, vinda de um movimento de ampliação de instrumentos de acesso à Justiça. Assim, escolhe-se a mediação pelo princípio relativo à adequação. O esvaziamento de processos do judiciário, por sua vez, deve ser consequência e não um motivo para a existência da mediação.

Em resumo, nesta categoria de conteúdos evidenciaram-se as dificuldades apresentadas pelas participantes da pesquisa, desde a sobrecarga de trabalho pelo número restrito de profissionais da Psicologia atuantes no Poder Judiciário de Santa Catarina até, para aqueles que atuam na mediação, a necessidade de realizarem diversas outras atividades além da mesma, o que pode incorrer em psicopatologias do trabalho. Ao mesmo tempo, a desproporção de profissionais neste âmbito afeta a interação com outras Ciências. Ainda, ficou evidente que distorções acerca do propósito da mediação tornam a atuação complexa e podem levar ao seu descrédito. 


\title{
Categoria 2: A prática da mediação familiar significada como uma oportunidade de adquirir novos conhecimentos
}

Nesta categoria, foram agrupados os significados da prática de mediação familiar considerada como um método adequado de resolução de conflitos e que possibilita, ao mesmo tempo, aprendizagem continuada aos profissionais envolvidos.

A prática de mediação familiar para mim gerou aprendizado em relação às questões envolvendo a dinâmica familiar, especialmente sobre conflitos envolvendo rupturas conjugais e intergeracionais. Ainda, a compreensão sobre a avaliação psicológica em situações de disputas de guarda, visitas, etc.; que uso um pouco das práticas da mediação (E1).

$\mathrm{Na}$ mediação se tem oportunidade de aplicar algumas técnicas oriundas da Psicologia, o que nos proporciona desenvolver habilidades. A mediação possibilita que o profissional haja de maneira mais focada nas relações familiares, amenizando as situações de estresse, estimulando o diálogo e o empoderamento das pessoas, para que consigam criar estratégias para resolver o conflito existente (E2).

\begin{abstract}
Verificou-se que a mediação familiar é entendida pelas participantes como um campo compatível com suas competências profissionais e que possibilita contínuo aprendizado. O conhecimento técnico tem a função preponderante na aproximação da teoria com a prática, aliando-se à produção do conhecimento e, desse modo, a experiência de mediar possibilita a aplicação de métodos a partir de sua prática, além de favorecer a ampliação e o desenvolvimento de novos métodos de solução de conflitos (Oliveira, 2010).
\end{abstract}

Evidenciou-se ainda que a mediação pode ser uma oportunidade de, em meio ao rigor do âmbito judicial, possibilitar um olhar ao sujeito em sua subjetividade, fortalecendo suas potencialidades e sua abertura ao diálogo com o outro, conforme mencionou E2: “observa-se que as trocas de experiências e a oportunidade de um diálogo mais centrado estimula as pessoas à pacificação social”. Ainda, de acordo com E3: "a Psicologia ganha, bem como, o Poder Judiciário e os jurisdicionados ganham a 
possibilidade de buscarem a solução de seus conflitos através de métodos alternativos, promovendo bem-estar e a paz social e prevenindo litígios e suas consequências".

Quando um trabalho de mediação é realizado de forma adequada, o benefício é compartilhado com uma amplitude maior entre todos os envolvidos, tanto no nível pessoal, como no social, o que confere um espaço de aprendizagem aos profissionais envolvidos, tanto da Psicologia como de outras áreas. Acerca disso, foram recorrentes as falas que indicam a interdisciplinaridade na mediação como uma oportunidade de aperfeiçoamento, como ilustra a seguinte participante: "A mediação é realizada em duplas de mediadores e essas interações são muito ricas” (E1). Em termos das relações interdisciplinares da Psicologia com o Direito, está foi evidenciada como um fator complementar na visão das participantes da pesquisa. Neste ponto, concorda-se com Trindade (2014), que diz que ambas as Ciências têm um destino comum, visto que possuem o mesmo objeto de estudo, o comportamento humano, porém, cada qual com suas especificidades. A esse respeito, E4 afirmou que "A relação entre profissionais do Direito e da Psicologia é de saberes complementares e devem compor para juntos alavancar a cultura da resolução mais pacífica de conflitos, como é a mediação".

Cabe considerar nesta categoria sobre aspectos do conhecimento que a formação didática se mostra relevante, de modo que o mediador deve ser um sujeito que busca por estudo, aprofundando-se em técnicas de diversas áreas, pois a interdisciplinaridade constitui-se por conceitos de diferentes conhecimentos que sustentam a prática da Sociologia, Psicologia, Antropologia e Direito. Por isso, é essencial a aproximação dos assuntos pertinentes que contribuem para a formação de um perfil profissional e para o aperfeiçoamento da atuação do mediador (CNJ, 2016a; Dias, 2016; Oliveira, 2010). Deste modo, entende-se como fundamental e desafiadora a elaboração da prática interdisciplinar ainda nas instituições de ensino, a fim de que a relevância de tal experiência corrobore no momento de formação dos acadêmicos e perdure para a atuação futura (Cúnico, Arpini, Mozzaquaro, Silva \& Bopp, 2012). 


\section{Categoria 3: A prática da mediação familiar significada como importante ao desenvolvimento da Psicologia}

Esta categoria foi construída a partir dos significados atribuídos às questões que norteiam a presença do profissional de Psicologia no SMF. Os núcleos de conteúdos versam sobre os saberes à priori da profissão e a contribuição para a atuação enquanto mediador, os ganhos no desenvolvimento da ciência psicológica ao adentrar tal contexto e a importância da atuação de profissionais da Psicologia na capacitação de outros profissionais do SMF.

Os depoimentos dos participantes enfatizaram a atuação em Psicologia como privilegiada em termos de contemplar a compreensão das motivações e das relações humanas, a exemplo do seguinte: “A participação do profissional de Psicologia é muito importante, pois sua capacitação técnica permite melhor compreensão dos interesses trazidas pelos indivíduos nas sessões de mediação, com escuta qualificada, manejo adequando das situações de conflito" (E1). Como salienta Cavalcante (2015), o profissional psicólogo pode contribuir na mediação por possuir conhecimentos sobre a dimensão subjetiva das pessoas envolvidas, fundamentais à garantia de direitos e à efetivação da cidadania, por vezes, esquecidas no sistema de justiça tradicional, em virtude de burocracias, procedimentos e relações de poder. Acerca disso, as afirmações de E1, E2, E3 e E4 corroboram para essa compreensão: "O conhecimento psicológico permite uma melhor compreensão das dinâmicas relacionais e conflitivas, o que importante ao contínuo desenvolvimento da Psicologia” (E1); “A prática da Psicologia no contexto da mediação familiar significa buscar abrir caminhos possíveis para que as pessoas busquem alternativas para suas relações e conflitos, priorizando o diálogo" (E2); "O profissional pode trazer grande contribuição à mediação familiar, uma vez que os princípios norteadores de sua prática, as questões éticas e alguns instrumentos da Psicologia podem auxiliar na atuação como mediador" (E3); e, "Trata-se de uma área importante no contexto de tentativa de resolução de conflitos entre as pessoas, de forma menos litigiosa. Portanto, mais saudável e construtiva, que permite aprimoramento da própria Psicologia (E4). 
Evidenciou-se que os participantes da pesquisa compreendem que a participação da Psicologia no âmbito do Poder Judiciário está se construindo de forma a ser cada vez mais essencial, de modo a reconfigurar as relações de poder que movem, em muitos casos, os conflitos. Especificamente a atuação na mediação é repleta de conteúdo subjetivo e sensível, convergente às características da formação em Psicologia. No entanto, a falta de profissionais qualificados, como o psicólogo, tem incorrido em controvérsias na mediação, pois muitos profissionais atuam na mediação de maneira impositiva, o que é decorrente de seu treinamento. Nesse sentido, concorda-se com Melo (2013) ao considerar que a maioria destes conflitos causa um grande sofrimento psíquico aos envolvidos, o que torna essencial da presença de um mediador psicólogo no auxílio a essas demandas.

Ao mesmo tempo, a mediação adequada favorece o exercício da autonomia das partes para encontrarem uma solução por esforço próprio, pois prioriza a comunicação, demonstrando os caminhos para o amadurecimento cultural nacional, capaz de promover a pacificação social (Júnior \& Hecktheuer, 2016). Dentre os desafios aos profissionais da Psicologia que atuam como mediadores está o de estabelecer interação de seus conhecimentos com o saber jurídico, para além das técnicas no processo de escuta e das intervenções ao adentrar esse espaço (Melo, 2013), cujos aspectos também foram apontados pelas participantes. Portanto, o ofício dos profissionais da Psicologia no campo jurídico, no âmbito dos processos de mediação de conflitos familiares, deve estar continuadamente orientado a auxiliar as necessidades da população no processo de condução e resolução de impasses configurados juridicamente, considerando-se o contexto dos paradigmas culturais de afirmação das diferenças individuais e do compartilhamento de necessidades e sentimentos mútuos (Müller, Beiras \& Cruz, 2007).

Compreendeu-se o quão importante é que a Psicologia esteja pautada na virtude das demandas sociais ao expandir suas áreas de conhecimento, pesquisa e atuação. No SMF, é necessário que os profissionais desta Ciência sejam capazes de oscilar entre a ética do cuidado e a lógica da justiça, com o dever de observar e ampliar a visão da situação em si (Silva, 2016). Diante dessa proposta, constrói-se relevante a participação da Psicologia 
nas capacitações de outros profissionais em mediação familiar, o que tem sido demandado às participantes dessa pesquisa e foi informado pelas mesmas: "Atuo como instrutora juntos a outros profissionais" (E1); "Nas capacitações é essencial a presença de um profissional da psicologia principalmente para dar mais sensibilidade aos processos familiares e ajudar os outros profissionais a olhar para o caso concreto com a complexidade humana e das relações humanas" (E2); e, "O psicólogo tem possiblidade e habilidade para ser instrutor na formação de mediadores” (E3). No entanto, das quatro participantes da pesquisa, apenas uma realiza, além da função de mediadora, a de instrutora para a mediação de profissionais de diversas formações. Constatou-se ainda que as participantes da pesquisa foram capacitadas somente por profissionais do Serviço Social, sem que tenha havido trocas de experiências com outros profissionais do campo da Psicologia, mesmo de outros Estados. Questiona-se, neste sentido, se a transmissão de conhecimentos tem sido privilegiada e efetiva na formação de mediadores, bem como se a interdisciplinaridade tem sido fortalecida.

A partir dessa categoria, entendeu-se que a atuação em mediação familiar tem significado às participantes o desenvolvimento da própria Psicologia e consiste em um campo de oportunidades e desafios aos profissionais da área.

\section{Categoria 4: a prática da mediação familiar significada como central para se fomentar a cultura do trabalho ampliado na Psicologia}

Esta categoria congrega núcleos de conteúdo acerca das competências consideradas importantes aos profissionais que atuam na mediação e sobre o uso das técnicas contidas no manual de mediação judicial do CNJ (2016a), de acordo com a percepção das participantes da pesquisa. O desenvolvimento das competências e adequada utilização das técnicas norteiam a acessibilidade e a valorização dos profissionais, fomentando a cultura do trabalho ampliado na Psicologia.

Destaca-se a ideia de que a mediação surgiu de saberes multiprofissionais, que a enriqueceram, e isso implica, necessariamente, na forma 
como o mediador vê sua profissão, pois o conhecimento tem à priori um papel importante no modo em que influencia a atuação na mediação, em virtude de sua profissão de origem (Müller, 2007). As competências destacadas pelas participantes apontam para a cultura de trabalho ampliado na Psicologia, conforme constam nos depoimentos seguintes: "Neutralidade, imparcialidade, paciência, capacidade de escuta, olhar atento para os mediandos, em todas as suas expressões, capacidade de acolhimento, qualificação técnica nas práticas de mediação familiar" (E1). Também é apontado: "Escuta ativa, validação de sentimentos; estabelecer rapport e atitude colaborativa sobre os vínculos e relações familiares. O psicólogo favorecendo o desenvolvimento relacional entre os envolvidos” (E2). E3 destaca: "Capacidade de ouvir, tolerância, paciência, controle das emoções e não julgar são algumas das competências necessárias para a atuação, a meu ver" (E3). E4 ainda chama atenção: "Habilidade para promover o diálogo entre as pessoas, o acolhimento, a escuta, a objetividade. O psicólogo precisa saber levantar informações, focalizar os temas, auxiliar na redação do acordo, ser capaz e identificar as emoções” (E4). Diante dos depoimentos, retoma-se Müller (2007) ao ressaltar que algumas competências estão respectivamente ligadas entre si. Estabelecer rapport, escutar ativamente e demonstrar empatia, por exemplo, formam um conjunto de competências afins. Do mesmo modo, estão vinculadas à promoção do reconhecimento recíproco, orientando a uma postura colaborativa nesta atuação.

Em linha com as competências salientadas do profissional da Psicologia, as participantes destacaram as técnicas de mediação consideradas mais importantes dentre as presentes no manual de mediação judicial do CNJ (2016a), quais sejam: despolarizar a relação, evitar julgamentos, gerir emoções, analisar intenções, compreender comportamentos, tornar o processo construtivo, realizar a audição de propostas, organizar questões e interesses, recontextualizar e a inversão de papéis. Desse modo, compreendeu-se nesta categoria que as competências da atuação em Psicologia estão entrincheiradas às técnicas previstas pelo $\mathrm{CNJ}$, o que favorece a cultura do trabalho ampliado. No depoimento de E3, tem-se essa amplitude destacada: "são necessários conhecimentos sobre a família e o direito da família, com o olhar a partir de diversas Ciências” (E3). 
A fim de fomentar a cultura do trabalho ampliado, cabe dar relevância ao fato de o mediador demonstrar entendimentos jurídicos das questões que norteiam cada caso de mediação, ou seja, a necessidade de repassar informações e orientações fundamentadas. No entanto, o mediador não deverá utilizar o entendimento jurídico para avaliar e sugerir as bases do acordo (Müller, 2007). Desse modo, torna-se fundamental a realização de capacitação frequente, central à atualização e às trocas de conhecimentos entre os profissionais, o que foi ressaltado por E2 e E3 como algo positivo do Poder Judiciário de Santa Catarina, que tem promovido tais oportunidades aos profissionais.

De acordo com manual de mediação judicial do CNJ (2016a), os tribunais deverão disponibilizar cursos de treinamento e aperfeiçoamento, pois conciliadores, mediadores e outros especialistas em contato com métodos consensuais de solução de conflitos deverão realizar aperfeiçoamento permanente e a avaliação do usuário. Observando as diretrizes curriculares estabelecidas pelo CNJ, tais cursos necessitam ser compostos de estágio supervisionado. "Entende-se fundamental a profissionalização do mediador familiar, independente de sua formação acadêmica, a fim de que se estabeleça uma cultura de mediação, se garanta a remuneração, o comprometimento dos mediadores, a continuidade e qualidade dos serviços" (E3). "O que poderia haver, seriam mais campanhas e incentivos para fomentar a mediação familiar. Também ter equipes atuando especificamente com isso, e não contar apenas com estratégias e voluntários no setor, como é o caso da comarca" (E4).

Verificou-se, nesta categoria, a necessidade de valorização, tanto do procedimento coerente quanto dos profissionais, a fim de estimular a cultura do trabalho ampliado e participativo. Acerca disso, conforme Tartuce (2008), os meios alternativos de conflitos são uma tendência mundial, não só em face do sistema jurídico, mas também pela evolução da sociedade rumo a uma cultura participativa, por meio da qual o cidadão torne-se o protagonista da busca por uma solução consensual. 


\section{Categoria 5: a prática da mediação familiar significada como desafiadora e ampla.}

Nesta categoria foram agrupados conteúdos sobre a prática da mediação familiar significada como desafiadora e ampla às participantes, devido, em especial, à abrangência dos casos mediados e, ao mesmo tempo, à necessidade de olhar suas particularidades. O depoimento de E1 é ilustrativo: "Alguns casos em que se percebe que a demanda não é para mediação e sim para psicoterapia, como alcoolismo, episódios depressivos, etc. Nesse caso, é realizado o encaminhamento para outros serviços" (E1). Para a compreensão do contexto e dos conflitos familiares, faz-se necessária a procura de diversas referências e Ciências que também se debrucem ao estudo do ser humano em sua magnitude, não apenas como sujeitos de direitos, mas também, como sujeitos de desejos. Adequar a justiça à vida e não engessar a vida dentro de normas jurídicas, editadas, por vezes, olhando para o passado na tentativa de reprimir o livre exercício da liberdade, é um grande desafio. $\mathrm{O}$ âmbito das demandas das famílias lida, sobretudo, com relações dotadas de sentimentos, movidas por medo e inseguranças; são pessoas que sofrem desencantos e frustrações e, por vezes, procuram no judiciário ouvidos aos seus clamores (Dias, 2016).

Em termos da abrangência e das particularidades da atuação, as problemáticas de ordem social perpassam os moldes da mediação de conflitos como, por exemplo, a drogadição, a questão do desemprego, situações de violência, etc. $\mathrm{O}$ cuidado adicional com essas questões necessita ser dispendido através de ações que envolvem uma rede de atenção social, ou seja, escapam ao aspecto puramente legal e emocional do conflito familiar e adentram na esfera social de promoção de saúde e bem-estar dos sujeitos (Melo, 2013). Diante disso, o trabalho em rede foi considerado essencial pelas participantes, a fim de conferir uma amplitude maior de ações para as demandas encontradas, indo ao encontro do fortalecimento e da integridade dos serviços com foco na cidadania:

Não entendo possível e adequando a continuidade da intervenção psicológica pelo mesmo profissional que realizou a mediação judicial. No, entanto, alguns casos, quando não alcançam a resolução dos conflitos, na separação 
não aceita por um dos ex-cônjuges, adoecimento psíquico, prejuízos emocionais às crianças, situações de violência intrafamiliar, entre outras, por vezes, devem ser encaminhadas para acompanhamento psicológicos, desvinculando da mediação (E3).

Desse modo, a mediação se destaca como uma intervenção capaz de resolver conflitos de modo diferenciado, para além da resolução da demanda judicial (Cúnico et al., 2012).

Cabe considerar ainda que os requisitos éticos se tornam primordiais para garantir os encaminhamentos da mediação, a fim de equivaler-se de sua imparcialidade, auxiliando igualmente aos sujeitos, de modo a contribuir para a potencialização de suas vidas. De acordo com Dias e Souza (2013), a ética perpassa a postura do mediador, por meio da observância aos princípios que regem sua atuação, de forma a possibilitar a construção de um ambiente propício para a comunicação e o acesso à justiça.

No que concerne à ética, foram recorrentes os depoimentos que consideraram o ambiente físico como um desafio para a realização da mediação, de modo que nem todos os espaços possibilitam o sigilo, a acolhida e distanciamento do rigor de que se impregna o Judiciário. Acerca disso, as participantes elencaram algumas impossibilidades, conforme depoimentos a seguir: "Hoje o espaço disponibilizado não é dos mais acolhedores. Embora a equipe consiga trabalhar de forma positiva, estamos buscando alternativas para deixar a sala de mediação um espaço mais acolhedor aos jurisdicionados" (E2). "Não temos ambiente exclusivo para mediação. Dessa maneira, poderia ser mais adequado, com espaço exclusivo e com a disposição de móveis e outros materiais sugeridos pelos estudos sobre o tema” (E3).

O ambiente de mediação pode compilar uma linguagem não verbal, a partir de como as pessoas envolvidas se comportam. Assim, cabe ter um cuidado em propiciar um ambiente que deverá transparecer conforto e privacidade, uma vez que as partes deixarão de se preocupar com a controvérsia em si, caso sintam-se desconfortáveis, deslocando sua preocupação para algo bastante improdutivo à mediação. Assim, fatores ambientais como a cor das salas, música ambiente e aromas podem ser úteis para melhorar a qualidade ambiental (CNJ, 2016a). 


\section{CONSIDERAÇÕES FINAIS}

Por meio das cinco categorias de significados da prática da mediação identificadas neste estudo, entende-se que o campo pode ser considerado como em construção. Pode-se evidenciar, desse modo, a relevância da compreensão do comportamento humano em casos de resolução dos conflitos familiares, sendo os saberes psicológicos, a escuta qualificada e o cuidado psicológico instrumentos essenciais a fim de propiciar uma afabilidade adequada aos sujeitos.

Cabe trazer atenção à necessidade de produção de conhecimentos, favorecendo a elaboração de um trabalho ampliado e colaborativo, a partir das relações profissionais entre psicólogos e juristas, ainda que isso seja desafiador. Entende-se possível a complementariedade entre os saberes e o desenvolvimento das competências profissionais, necessárias à realização deste fazer profissional, sem desconsiderar a subjetividade humana. Vislumbra-se, ainda, que a interação entre os saberes se torna essencial à expansão da cultura da mediação familiar.

O posicionamento da profissão ao demonstrar as possibilidades do seu trabalho deverá mover-se em direção à expansão e à construção de possibilidades de superação dos significados. Torna-se impositivo abrir caminhos para a inserção gradativa da Psicologia e para a valorização do trabalho realizado por seus profissionais no ambiente jurídico. Esse desafio foi evidenciado quando as participantes desta pesquisa demarcaram a ausência ou o desinteresse pelo trabalho em grupo nas Instituições, fragilizando e até impossibilitando o fortalecimento das práticas do SMF. Diante disso e por fim, os apontamentos suscitados orientam para um compromisso ético e político da Psicologia com os sujeitos em discórdia, possibilitando, ao mesmo tempo, o posicionamento crítico e o saber deste profissional ao se deparar com as determinações no pleito do judiciário, constituindo-se, assim, em uma ferramenta importante para o desenvolvimento de potencialidades humanas que permitam à sociedade transitar do conflito ao diálogo. 


\section{REFERÊNCIAS}

Almeida, T. (2017). Mediação não é ferramenta para desafogar Judiciário. Adambrasil. Recuperado de http://www.adambrasil.com/mediacaonao-e-ferramenta-para-desafogar-judiciario-afirma-especialista/. Acesso em 13 Set. 2017.

Barbieri, C. M., \& Leão, T. M. S. (2012). O papel do psicólogo jurídico na mediação de conflitos familiares. Recuperado de http://www. psicologia.pt/artigos/ver_artigo.php?codigo=Ao66o. Acesso em 3 Maio 2017.

Barbosa, Á. A. (2002). A Política Pública da Mediação e a Experiência Brasileira. Recuperado de http://www.ibdfam.org.br/_img/ congressos/ anais/204.pdf. Acesso em 28 Abr. 2017.

Bardin, L. (2011). Análise de Conteúdo (70 Ed.). Lisboa: LDA.

Cavalcante, P. R. (2015). Contribuições da Psicologia no acesso à Justiça: reflexões sobre a atuação de psicólogas/os na Defensoria Pública do Estado de São Paulo. (Dissertação de Mestrado). Universidade de São Paulo, São Paulo. Recuperado de http://www.teses.usp.br/ teses/disponiveis/47/47134/tde-07082015-112201/pt-br.php. Acesso em 08 Mar. 2017.

Conselho Nacional de Justiça - CNJ (2016a). Manual de Mediação Judicial, 6. ed. Brasília: CNJ. Recuperado de http://www.cnj.jus.br/files/ conteudo/arquivo/2016/07/f247f5ce6odf2774c59d6e2dddbfec54. pdf. Acesso em 28 Mar. 2017.

Conselho Nacional de Justiça - CNJ (2016b). Relatório Justiça em Números traz índice de conciliação. Recuperado de http://www.cnj.jus.br/ noticias/cnj/83676-relatorio-justica-em-numeros-traz-indice-deconciliacao-pela-1-vez2016. Acesso em 02 Abr. 2017.

Conselho Nacional de Justiça - CNJ. (2016c). Justiça em Números. Infográficos: ano-base 2015. Brasília: CNJ. Recuperado de http://s. conjur.com.br/dl/justicaemnumeros-2016-infograficos.pdf Acesso em 10 Mar. 2017. 
Conselho Regional de Psicologia. (2017). CRP-SC participa de audiência pública sobre a terceirização no TJSC. Recuperado de http://www. crpsc.org.br/noticias/crp-sc-participa-de-audiencia-publica-sobrea-terceirizacao-no-tjsc. Acesso em 12 Set. 2017.

Costa, F. de N. (2006). O Trabalho dos Psicólogos em Organizações de Justiça do Estado de Santa Catarina (Dissertação de Mestrado). Universidade Federal de Santa Catarina, Florianópolis. Recuperado de http://fatorhumano.ufsc.br/files/2010/12/FL\%C3\%81VIA-DENOVAES-COSTA.pdf. Acesso em 10 Mar. 2017.

Cúnico, S. D., Arpini, D. M., Mozzaquaro, C. O., Silva, M. L., \& Bopp, M. E. T. (2012). Psicologia e Mediação Familiar em Núcleo de Assistência Judiciária. Boletim de Psicologia, LXII(137), 141-154. Recuperado de http://pepsic.bvsalud.org/pdf/bolpsi/v62n137/v62n136ao4.pdf. Acesso em 16 Set. 2017.

Dias, F. A, \& Souza, J. L. (2013). O Mediador (Perfil, Atuação e Ética) na Resolução dos Conflitos. Revista Jurídica, 17(34), 225-251. Recuperado de http://proxy.furb.br/ojs/index.php/juridica/ article/ view/4059. Acesso em 12 Set. 2017.

Dias, M. B. (2016). Manual de direito das famílias (11 Ed.). São Paulo: Editora Revista dos Tribunais.

Diehl, A. A. (2004). Pesquisa em Ciências Sociais Aplicadas: Métodos e Técnicas. São Paulo: Prentice Hall.

Freitas, F. R., Cezne, G. M., Hubner, J. M., Pazzobon, K. M., Rizzatti, D. B., Kunn, K. W., \& Staevie, M. E. S. (2011). Mediação de conflitos sob a ótica psicanalítica: um relato de experiência de acadêmicas de psicologia. 1 (1), 112-117. Recuperado de http://online.unisc.br/ acadnet/anais/index.php/jornada_psicologia/article/view/10215/41. Acesso em 3 Maio 2017.

Gomes, M. B. (2013). Em conflito: conhecimento e confrontação. Revista Famecos, 2o(3), 618-633. Recuperado de http:// revistaseletronicas.pucrs.br/ojs/index.php/revistafamecos/article/ viewFile/12198/10788. Acesso em 04 Maio 2017. 
Gondim, L. V. C. (2012). Mediação Familiar: o resgate ao reconhecimento da pessoa humana nas relações familiares. Recuperado de http:// tmp.mpce.mp.br/esmp/publicacoes/Edital-n-03-2012/Artigos/ Lillian-Virginia-Carneiro-Gondim.pdf. Acesso em 28 Abr. 2017.

Júnior, E. G. B., \& Hecktheuer, P. A. (2016). A Mediação como Instrumento da Desjudicialização e Pacificação Social. Anais da V Semana Acadêmica de Direito da FCR, Porto Velho. 1 (1), 87-127. Recuperado de http://www.fcr.edu.br/revista/index.php/anaissemanadedireito/ article/view/47. Acesso em 20 Set. 2017.

Melo, K. A. L. (2013). Mediação De Conflitos Familiares: Relações entre os saberes da Psicologia do Direito no campo jurídico. (Dissertação de Mestrado). Universidade Federal de Pernambuco, Recife. Recuperado de http://repositorio.ufpe.br/handle/123456789/10138. Acesso em 2 Mar. 2017.

Mello, P. P., \& Jaeger, F. P. (2015). A atuação do psicólogo como mediador de conflitos no contexto jurídico. Recuperado de https://www. academia.edu/25839726/A_ATUAÇÃO_DO_PSICÓLOGO_COMO_ MEDIADOR_DE_CONFLITOS_NO_CONTEXTO_JURIDICO em 2 Abr. 2017.

Minayo, M. C. S. (Org.) (2004). Pesquisa social: teoria, método e criatividade. Petrópolis: Vozes.

Müller, F. G. (2007). Competências Profissionais do Mediador de Conflitos Familiares (Dissertação de Mestrado). Universidade Federal De Santa Catarina, Florianópolis. Recuperado de https://repositorio. ufsc.br/xmlui/handle/123456789/89767. Acesso em 7 Mar. 2017.

Müller, F. G., Beiras, A., \& Cruz, R. M. (2007). O trabalho do psicólogo na mediação de conflitos familiares: reflexões com base na experiência do serviço de mediação familiar em Santa Catarina. Aletheia, 26, 196-209. Recuperado de http://pepsic.bvsalud.org/scielo. php?script $=$ sci_arttext\&pid=S1413-03942007000200016. Acesso em 07 Mar. tartuce2017. 
Nascimento, D. M. (2016). Psicologia na relação com o Sistema de Justiça. Psicologia em Movimento, 1 (6), 59-61. Recuperado de http://www. crpsc.org.br/ckfinder/userfiles/files/Revista6(3).pdf. Acesso em 4 Abr. 2017.

Nunes, A. C. O. (2016). Manual de mediação: guia prático da autocomposição. São Paulo: Editora Revista dos Tribunais.

Oliveira, L. R. F. (2010). Mediação de Conflitos Familiares: perspectiva teórica e processo de intervenção. Revista de Psicologia da IMED, 2(2), 441-448. Recuperado de https://seer.imed.edu.br/index.php/ revistapsico/article/view/57. Acesso em 10 Set. 2017.

Otaran, P. M., \& Amboni, G. (2015). A caracterização do trabalho do psicólogo no Tribunal de Justiça de Santa Catarina. Revista de Ciências Humanas, 49(2), 94-117. Recuperado de file://C:/Users/ Usuario/Downloads/36205-140612-1-PB.pdf. Acesso em 23 Abr. 2017.

Poder Judiciário de Santa Catarina - PJSC. (2017). Programas alternativos de solução de conflitos. Recuperado de https://www.tjsc.jus.br/ programa-servico-de-mediacao-familiar\#. Acesso em 10 Mar. 2017.

Santos, P. C. M. (2013). A atuação do psicólogo junto à Varas de Família: reflexões a partir de uma experiência. (Dissertação de Mestrado). Universidade de São Paulo, São Paulo. Recuperado de http://www. teses.usp.br/teses/disponiveis/ 47/47131/tde-09102013-105048/ pt-br.php. Acesso em 10 Mar. 2017.

Santos, R. S., \& Júnior, R. F. M. (2011). Síndrome de Alienação Parental e Mediação Familiar - do conflito ao diálogo. (6), 1-24. Recuperado de http://www.revistas.unifacs.br/index.php/redu/article/view/1410. Acesso em 6 Mar. 2017.

Silva, D. M. P. (2016). Psicologia jurídica no processo civil brasileiro: a interface da psicologia com o direito nas questões de família $e$ infância (3 Ed.). Rio de Janeiro: Forense.

Tartuce, F. (2008). Mediação nos conflitos civis. São Paulo: Editora Método. 
Tolfo, S. R., \& Piccinini, V. (2007). Sentidos e Significados do Trabalho: explorando conceitos, variáveis e estudos empíricos. Brasileiros. Psicologia \& Sociedade, 19(1), 38-46. Recuperado de http://www. scielo.br/pdf/psoc/v19nspe/v19nspea07.pdf. Acesso em $28 \mathrm{Abr}$. 2017.

Trindade, J. (2014). Manual de Psicologia para Operadores do Direito (7 Ed.). Porto Alegre: Livraria do Advogado Editora Ltda.

Trindade, J. (2017). Psicologia e Judiciário. Congresso de Psicologia da Região Meio Oeste, Extremo Oeste de Santa Catarina, São Miguel do Oeste, 1.

Vieira, S. S. (2014). Mediação de conflitos familiares: acesso à justiça pelo diálogo. Revista Jus Navigandi, 3985. 1-2. Recuperado de https:// jus.com.br/artigos/28971. Acesso em 02 Abr. 2017.

Vieiera, L. (2010). Consultório Etimológico. Recuperado de http:// origemdapalavra.com.br/site/palavras/mediador/. Acesso em 14 Mar. 2017.

Recebido em 29/08/2018

Aceito em 06/09/2019 